\begin{tabular}{|c|c|}
\hline ב & $\begin{array}{c}\text { International Journal of Current Research } \\
\text { and Academic Review }\end{array}$ \\
\hline $\begin{array}{l}\text { EXCELLENT } \\
\text { PUBLISHERS }\end{array}$ & 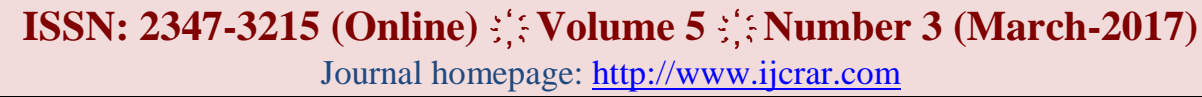 \\
\hline
\end{tabular}

doi: https://doi.org/10.20546/ijcrar.2017.503.009

\title{
Electrical Pulse-Mediated Veliparib for Effective Treatment of Triple Negative Breast Cancer: An in vitro Model Study
}

\author{
Lakshya Mittal $^{1}$, Vishak Raman ${ }^{2}$, Ignacio G. Camarillo ${ }^{2,3}$ and Raji Sundararajan ${ }^{1 *}$ \\ ${ }^{I}$ School of Engineering Technology, Purdue University, Indiana, USA \\ ${ }^{2}$ Department of Biological Sciences, Purdue University, Indiana, USA \\ ${ }^{3}$ Purdue University Center for Cancer Research, Indiana, USA \\ *Corresponding author
}

\section{Abstract}

Use of Poly (ADP-ribose) polymerase (PARP) inhibitors has received major attention as therapeutic agents for the treatment of breast cancers with or without mutations in BRCA1 or BRCA2. Thus, it can be effectively used for triple negative breast cancer (TNBC), which lacks the conventional receptors that many chemo drugs attack. Veliparib, a PARP agent is used as $2^{\text {nd }}$ line of treatment along with platinum compounds. It is of practical interest to study the efficacy of Veliparib alone as an anticancer drug for TNBC. Towards this, in this research, we studied the efficacy of Veliparib on MDA-MB-231, human triple negative breast cancer cells. A concentration of $330 \mu \mathrm{M}$ was used for this purpose. In addition, to enhance the uptake of Veliparib against the plasma membranes of the cells, electroporation technique is used, which involves the local application of electrical pulses to open pores, which enables easy drug passage across the cell membranes. Thus, the objective of this study is to identify the potential of Veliparib and Electroporation as an alternate combinational therapy for TNBCs. Electrical pulses of high intensity, low duration $1200 \mathrm{~V} / \mathrm{cm}, 100 \mu \mathrm{s}, 8$ pulses and low intensity high duration $500 \mathrm{~V} / \mathrm{cm}, 20 \mathrm{~ms}, 8$ pulses are used in this study. Cell viabilities were measured immediately, as well as after 24 , 48 and 72 hours of treatment. The results indicate cell viabilities of $70 \%$ immediately after Veliparib+electrical pulses treatment, compared to $94 \%$ with drug only, indicating the potential of the synergy of electrical pulses+Veliparib. The viabilities were lower by 11 to 13 times after 72 hours. This promising treatment is transferrable to clinical practice.
\end{abstract}

\section{Article Info}

Accepted: 18 March 2017

Available Online: 25March 2017

\section{Keywords}

Triple Negative Breast Cancer, Veliparib, PARP inhibitors, Electrochemotherapy, Electrical Pulses

\section{Introduction}

With 1.7 million new cases (11.9\%) in 2012, breast cancer was the second most common cancer and ranked $5^{\text {th }}$ with 522,000 of deaths $(6.4 \%)$ (Ferlay et al., 2014). Triple Negative Breast Cancer (TNBC) contributes to about $12 \%$ to $17 \%$ of all invasive breast cancers in
Western populations (Foulkes et al., 2010). Studies indicate that TNBC is more common among Black and Hispanic women compared to White women (Desantis et al., 2013). In India, TNBC is more prevalent with as many as one in three women with breast cancer could have triple negative (Sandhu et al., 2016). Breast cancer patients are usually screened for an expression of 
estrogen receptor (ER), progesterone receptor (PR) and evaluated for the amplification of HER-2/Neu. TNBCs do not display these expressions; hence it is more difficult to treat (Chavez et al., 2011). Conventional therapies which target any of these receptors to treat breast cancers are not helpful for TNBC. Keam, B. et al. indicate that the probability of overall survival rate of TNBC patients is a poor $2.1 \%$, while the relapse survival rate is mere $0.1 \%$ (Keam et al., 2007). Thus, there is a critical need of alternate techniques to treat TNBC.

In clinical trials, Gemcitabine + Cisplatin is used as a first line treatment for metastatic TNBC, and Veliparib and carboplatin is also used to treat TNBC (Zhang et al., 2014; Stover et al., 2016). Veliparib is a Poly (ADP Ribose) Polymerase (PARP) inhibitor that stops the repairing of DNA of cancer cells, and hence serves as an anticancer drug (Velic et al., 2015). The PARP function is critical in restoring the genome following the accidental single strand breaks in replication fork, which are equivalent to double stranded breaks in double helix (Weinberg, 2007). PARP inhibitors inhibit PARP enzyme to undermine DNA repair and improve the effect of DNA-damaging agents (Figure 1; Sonnenblick et al., 2014).

Recently Murai et al., (2012) have suggested an additional mode of actions of PARP inhibitors. They have suggested that PARP inhibitors cause the localization and trapping of PARP proteins at DNA repair site, which blocks the DNA replication and thus increasing toxicity in cells. Thus the reduced efficiency of DNA repair by PARP inhibitors in cancer cells can be attributed to the inhibition and trapping of PARP enzyme.

Fig.1 Mechanism of action of PARP to cause cell death (Sonnenblick et al., 2014)

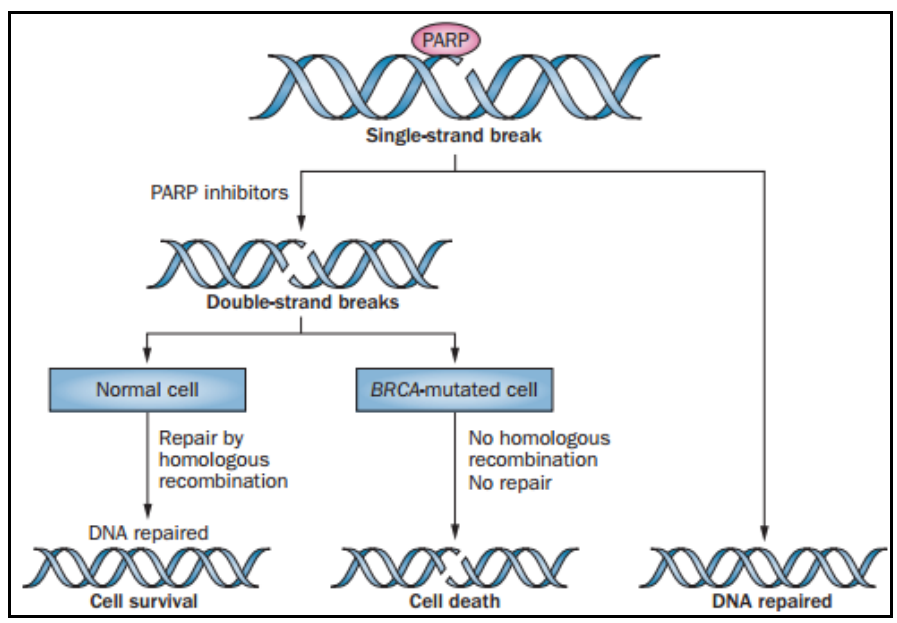

A study by Rozensal et al., (2009) suggests that the phenanthridine derived PARP inhibitors (for example, PJ-34) are effective in breast cancer cells without BRCA1 or BRCA2 mutation. They have demonstrated that PARP inhibitors promote cell cycle arrest at G2/M and cell death in MCF-7 and MDA-MB-231 breast cancer cell lines, which lack BRCA1 and BRCA2 mutation. Therefore, PARP inhibitors are sensitive to MDA-MB-231 TNBC cell line as well. Thus, interest has been growing towards PARP inhibitors in combination with DNA damaging drugs (Carboplatin, Paclitaxel and Cisplatin etc.) to treat cancers with or without BRCA mutations. However, the efficacy of various PARP inhibitors in TNBC without BRCA mutations is not yet fully established.

Veliparib is a potent PARP inhibitor very effective in the treating variety of cancers with poor prognoses (www.onclive.com). Veliparib has been shown to improve the antitumor action of various DNA damaging agents such as temozolomide, cyclophosphamide, platinum, and radiation in preclinical models of melanoma, and breast and colon cancer (Donawho et al., 2007). It has been used with platinum chemo drug, carboplatin in triple negative breast cancer treatment in several Phase I and II clinical trials and have demonstrated the efficacy and safety of Veliparib in patients with triple negative breast cancer (Pahuja et al., 2015). Considering this, Veliparib has been used in present study as an anticancer drug against non BRCA mutated, Triple Negative breast cancer cell line MDAMB-231. Which is a spindle shaped invasive adherent type epithelial cell (www.cellbiolabs.com). This cell line was derived at M.D. Anderson Cancer Centre in 1973 from a Caucasian women through metastatic pleural effusion (Sonnenblick et al., 2014). MDA-MB-231 is classified as Claudin-low type among the five types of molecular classification in breast carcinoma. It exhibits intermediate response to chemotherapy (Holliday et al., 2011).

Electric potentials are not only limited to inorganic process but they can be found in living organism as well. Cells, the basic unit of life are known to possess ions and other charged molecules and thus exists a voltage difference between the cytoplasm and extracellular matrix, known as membrane potential $\left(\mathrm{V}_{\mathrm{m}}\right)$. Due to their electrical properties cells elicit a response to the external electric field. The membrane potential in cancerous cells has been observed to be depolarized than their normal counterparts (Redmann et al., 1972). The depolarization serves as signal for mitosis and DNA synthesis in normal 
and tumorous cells (Binggeli et al., 1986; Orr et al., 1972). Thus, considering the distinct bioelectric properties of cancer cells, it makes sense to use electrical pulse to treat cancers. Towards this, a novel physical technique, using electrical pulses and Veliparib is studied in this research for their efficacy on human TNBC cell line, MDA-MB-231. This technique involves the application of high intensity, short duration electric pulses which improve the permeability of cell membrane to facilitate increased uptake of the chemo drug (Teissie and Tsong, 1981). This therapy is particularly useful when big-3 (radiotherapy, chemotherapy and surgery) fail to treat cancers (Campana et al., 2009; Weaver, 2000). In the present study electrical pulses of varied magnitude and duration are used to enhance the uptake of Veliparib.

\section{Materials and Methods}

\section{The cells}

In present study, triple negative, basal type human adenocarcinoma epithelial breast cancer cell line, MDAMB-231 is used. This cell line is negative to ER, PR, and HER2 receptors. This cell line is low in Ki67, Ecadherin, claudin-3, clau-dinin-4 and claudinin-7 (Holliday et al., 2011).

\section{The drug}

Veliparib di-hydrochloride (ABT-888, Medchemexpress LLC, NJ) is used for this study. It is a 2-((R)-2methylpyrrolidin-2-yl)-1H-benzimidazole-4-

carboxamide di-hydrochloride with chemical formula $\mathrm{C} 13 \mathrm{H} 18 \mathrm{Cl} 2 \mathrm{~N} 4 \mathrm{O}$ and molecular weight of $317.21 \mathrm{~g} / \mathrm{mol}$. The structure is shown in figure 2. Veliparib inhibits both PARP-1 and PARP-2 with Kis (inhibitory constants) of 5.2 and $2.9 \mathrm{nM} / \mathrm{L}$, respectively (Wagner, 2015).

Fig.2 Chemical Structure of Veliparib (di-hydrochloride) (www.medchemexpress.com)

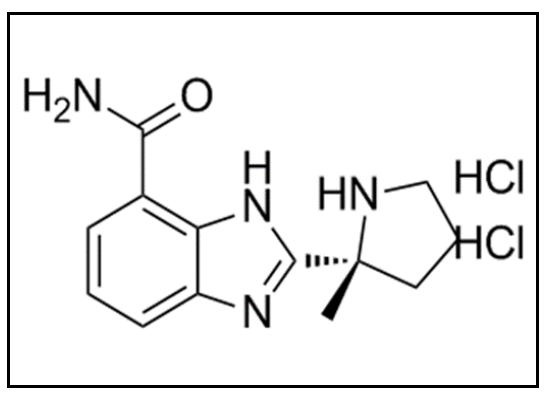

As seen with many PARP inhibitors, inhibition by Veliparib is quite selective and pharmacologically relevant concentration of Veliparib doesn't produce substantial effects on other receptors or ion channels. Veliparib is used to treat ovarian cancer, oral cancer, basal like breast cancer, pancreatic cancer, prostate cancer (Pahuja et al., 2015; Wagner, 2015).

The various side effects include gastrointestinal toxicity, nausea, vomiting, secondary leukemia, myelodysplastic syndrome, diarrhea, constipation, stomach pain, fatigue (Pahuja et al., 2015). These side effects can be effectively reduced if the concentration of Veliparib used in the treatment is reduced.

Veliparib, solubilized in DMSO at $10 \mathrm{mM} / \mathrm{mL}$ was used at to study the dose curve and a concentration of $330 \mu \mathrm{M}$ was used for the viability study.

\section{The electroporator}

BTX ECM 830 electroporator (Genetronics Inc., San Diego, CA) is used to generate unipolar square wave pulses with $1 \mathrm{~Hz}$ frequency. Table 1 shows the applied pulse parameters. The pulse parameters are based on previous research (Sundararajan et al., 2012; Gehl and Geertsen, 2000).

\section{The viability assays}

\section{Trypan blue assay}

$20 \mu \mathrm{L}$ of treated samples and $20 \mu \mathrm{L}$ of trypan blue were mixed together. From this mixture, $20 \mu \mathrm{L}$ was used to count both live and dead cells using the Nexcelom Bioscience Cellometer ${ }^{\circledR}$. The percentage viability was also directly measured using the Cellometer ${ }^{\circledR}$.

\section{MTT viability assay}

Colorimetric assay was performed using Thiazolyl Blue Tetrazolium Bromide (MTT- Methylthiazolyldiphenyltetrazolium bromide). This assay is useful for assessing cytotoxicity, cell viability and cell proliferation (Scott, 2003; Gerlier and Thomasset1986; Meerloo et al., 2011; Stockert et al., 2012).

MTT is a yellowish aqueous solution, and produces violet-blue formazan (Figure 3), on reduction by dehydrogenases and reducing agents present in metabolically active cells (Stockert et al., 2012). Formed MTT formazan can be estimated with the help of spectrophotometry after the extraction with organic solvents. The amount of MTT Formazan directly 
correlates with the number of living cells (Meerloo et al., 2011).

In this study, $4.8 \mathrm{mM}$ MTT stock solution was prepared in PBS solvent. $50 \mu \mathrm{L}$ of MTT stock solution was added into each well sometime (24 hours for studying dosage curve, and 24, 48, or 72 hours for measuring proliferation) after the treatment, which was further incubated at $37^{\circ} \mathrm{C}$ for 24 hours.

Fig.3 Chemical structure of MTT and its reduced product MTT formazan (Stockert et al., 2012)

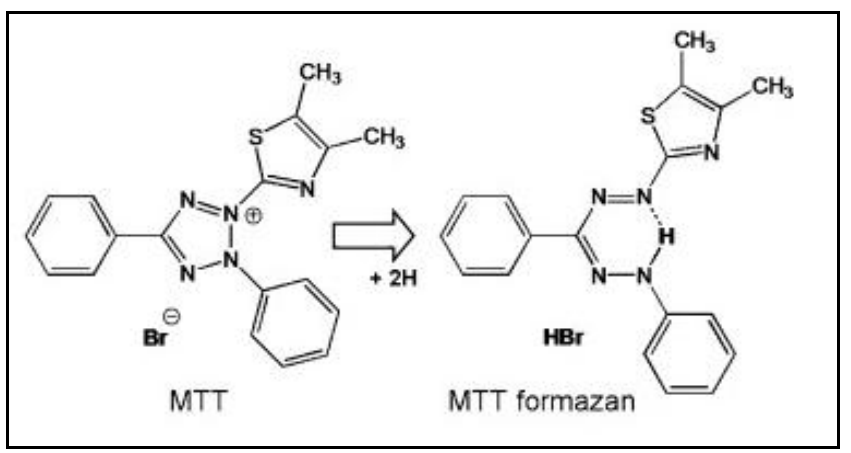

The media was discarded after 24 hours of incubation and $80 \mu \mathrm{L}$ of DMSO was added into each well to dissolve MTT formazan crystals. The 96 well plate was stirred for 15 minutes at $37^{\circ} \mathrm{C}$ to fully dissolve the formazan crystals. Spectrophotometer was used to study absorbance at the wavelengths of 570 and $630 \mathrm{~nm}$. The difference of absorbance at 570 and $630 \mathrm{~nm}$ was calculated for each cell and the resulting is subtracted by the difference in absorbance for the blank cell. The final viability was obtained after normalizing with control.

\section{Statistical analysis}

Analysis of variance (ANOVA) is performed on the data to find statistical difference. Constant variance and normality assumptions are verified for the data before performing ANOVA. Either one way or two way ANOVA has been performed, depending upon the number of factors. One way ANOVA is performed for dose curve study, where veliparib concentration is the single factor. The layout of the model is shown in table 2 .

The observations can be described with the effect model, as in equation 1. This equation is called the one way ANOVA model. In this model, $\mu$ is a constant overall mean which is common to all treatments, $C_{i}$ is the effect of $i^{\text {th }}$ level of concentration (treatment) which is unique to the $\mathrm{i}^{\text {th }}$ treatment. The effect model is a linear statistical model, with response variable $Y_{i j}$ as linear function of model parameters. $\varepsilon_{\mathrm{ij}}$ represents the error component, which is assumed to be independently and normally distributed random variable with mean 0 and variance $\sigma^{2}$ (Montgomery, 2013).

Yij $=\mu+C i+\varepsilon_{i j}\left\{\begin{array}{l}\text { i }=1,2 \ldots 7 \\ j=1,2,3\end{array}\right.$

where, $\sum_{i=1}^{7} C i=0 ; \varepsilon_{\mathrm{ij}} \approx \operatorname{NID}\left(0, \sigma_{\mathrm{D}}^{2}\right)$

Two way ANOVA is performed for viability study, with two factors: Treatment and Day. Viability in triplicates was measured for each combination of treatment and day. The Layout of the resulting two factor model is shown in table 3.

An effect model can be used to describe observation in two factorial experiments, as in equation 2 (Montgomery, 2013). Equation 2 is called two-factor or two way ANOVA model. $Y_{\mathrm{ijk}}$ is the cell viability for treatment level i, Day level $\mathrm{j}$, and $\mathrm{k}^{\text {th }}$ replicate. Also, $\mu$ is overall mean, $T_{i}$ is the effect of $i^{\text {th }}$ level of Treatment, $D_{j}$ is the effect of $j^{\text {th }}$ level of day, $\mathrm{TD}_{\mathrm{ij}}$ the effect of interaction between treatment and day, and $\varepsilon_{\mathrm{ijk}}$ is a random error component. The Treatment is a fixed effect while Day is random effect, making interaction as random effect. Taking the day as random effect represents the overall population of days.

Yijk $=\mu+T i+D j+T D i j+E i j k\left\{\begin{array}{l}i=1,2,3,4 \\ j=1,2,3 \\ k=1,2,3\end{array}\right.$

where, $\sum_{i=1}^{4} T i=0 ; D_{\mathrm{j}} \approx \operatorname{NID}\left(0, \sigma_{\mathrm{D}}^{2}\right) ; \mathrm{TD}_{\mathrm{ij}} \approx \operatorname{NID}(0$, $\left.\sigma_{\mathrm{TD}}^{2}\right) ; \sum_{i=1}^{4} T D i j=0 \quad \forall \mathrm{j} ; \varepsilon_{\mathrm{ijk}} \approx \operatorname{NID}\left(0, \sigma^{2}\right)$

Equation 3 represents the hypothesis of interest in ANOVA (Montgomery, D. C. (2013).

\section{H0: $\mu 1=\mu 2=\mu 3 \ldots=\mu n$ \\ H1: Not all means are equal}

where, $\mathrm{n}=$ number of independent comparison groups. $\mathrm{F}$ test was done to test hypothesis, as described (Montgomery, D. C. (2013).

When we reject null hypothesis of equal treatment means in ANOVA, all pair wise mean comparisons were tested using Tukey's test (Tukey, 1953; Abdi, 2010), as post F test analysis. JMP ${ }^{\circledR}$ software is used for statistical analysis. 


\section{The protocol}

Figure 4 shows the protocol used in this study. All experiments were performed in triplicate.

\section{Results and Discussion}

\section{Dose curve}

Figure 5 shows the dose curve obtained using MTT assay for the MDA-MB-231 cells treated with various doses of Veliparib. This dose curve indicates the effect of veliparib alone as an anti-tumor drug. The viabilities are normalized with control. The viability dropped from $88 \%$ at $1 \mu \mathrm{M}$ to $65.43 \%$ at $10 \mu \mathrm{M}$ and reduced to $43.99 \%$ at $50 \mu \mathrm{M}$. However, it increased to $54.22 \%$ at $100 \mu \mathrm{M}$ and reduces to 34.89 for $300 \mu \mathrm{M}$. The lowest viability of $23.57 \%$ is obtained for $330 \mu \mathrm{M}$. An increase in viability is observed with increase in dosage of Veliparib with $30.39 \%$ viability for $500 \mu \mathrm{M}$. This increase in viability could be attributed to the saturation of the drug, which correlates with the results obtained in another study by Lee, J.et al., where they report the $11 \%$ of cell kill at $50 \mu \mathrm{M}$ concentration of Veliparib. In the present study, we have chosen $330 \mu \mathrm{M}$ concentration of Veliparib to treat MDA-MB-231 cells with/out electrical pulses.

One way ANOVA was performed to detect the statistical significance difference among the various drug concentration. P-value ( $p<0.0001)$ obtained from F-test indicates the existence of significance difference among treatments. As a post F-test, comparison of means was done using Tukey's HSD test. Letter report obtained from test is indicated in the table 4 . The difference in the letters reported for two treatment levels, indicates that there isstatistically significantdifference between two treatments. Control with letter ' $A$ ' is significantly different from treatment levels 10, 50, 100, 300,330 and $500 \mu \mathrm{M}$, as none of them contain letter ' $\mathrm{A}$ ' in their report. On the other hand, control is not significantly different from $1 \mu \mathrm{M}$ treatment, as they both share letter ' $\mathrm{A}$ ' (Table $5)$.

\section{Viability study using cellometer}

Immediately after the treatment, Trypan Blue assay was used to determine the viability. Figure 6 shows the viabilities of the cell line without any treatment (control), Veliparib only, and then the combination of drug and electric pulses at $1200 \mathrm{~V} / \mathrm{cm}, 100 \mu \mathrm{s}, 8$ pulses, and $500 \mathrm{~V} / \mathrm{cm}, 20 \mathrm{~ms}, 8$ pulses. The control has a viability of $94.14 \%$, while the drug only has a viability of $93.8 \%$, indicating just a cell-kill of $6 \%$. This could be attributed to the aggressiveness of the TNBC cell line.

It can be seen that with the synergy of the electrical pulses and the PARP inhibitor, there is increased cell kill. With the high intensity, short duration electric pulses of $1200 \mathrm{~V} / \mathrm{cm}, 100 \mu \mathrm{s}, 8$ pulses, the cell-kill is about $13 \%$, with a viability of $87 \%$, while it is $30 \%$ with a viability of $70 \%$, for $500 \mathrm{~V} / \mathrm{cm}, 20 \mathrm{~ms}, 8$ pulses.

Table.1 Pulse parameters studied

\begin{tabular}{|c|c|c|c|}
\hline $\begin{array}{c}\text { S. } \\
\text { No }\end{array}$ & $\begin{array}{c}\text { Electric Field } \\
\text { Intensity V/cm }\end{array}$ & $\begin{array}{c}\text { Pulse } \\
\text { Duration }\end{array}$ & $\begin{array}{c}\text { No. of } \\
\text { Pulses }\end{array}$ \\
\hline 1 & 1200 & $100 \mu \mathrm{s}$ & 8 \\
\hline 2 & 500 & $20 \mathrm{~ms}$ & 8 \\
\hline
\end{tabular}

Table.2 The Layout of the statistical model for dosage curve

\begin{tabular}{|l|c|}
\hline $\begin{array}{c}\text { Veliparib } \\
\text { Concentration }(\boldsymbol{\mu M})\end{array}$ & Viability \\
\hline Control $(0 \mu \mathrm{M})$ & $\mathrm{xxx}$ \\
\hline 1 & $\mathrm{xxx}$ \\
\hline 10 & $\mathrm{xxx}$ \\
\hline 50 & $\mathrm{xxx}$ \\
\hline 100 & $\mathrm{xxx}$ \\
\hline 300 & $\mathrm{xxx}$ \\
\hline 330 & $\mathrm{xxx}$ \\
\hline 500 & $\mathrm{xxx}$ \\
\hline
\end{tabular}


Table.3 The Layout of the two factors statistical model for viability study

\begin{tabular}{|l|c|c|c|}
\hline \multicolumn{1}{|c|}{ Treatment } & \multicolumn{3}{c|}{ Day } \\
\hline Control & Day 1 & Day 2 & Day 3 \\
\hline Veliparib only & $\mathrm{xxx}$ & $\mathrm{xxx}$ & $\mathrm{xxx}$ \\
\hline $\begin{array}{l}\text { Veliparib }+1200 \mathrm{~V} / \mathrm{cm}, 100 \mu \mathrm{s}, 8 \\
\text { pulses }\end{array}$ & $\mathrm{xxx}$ & $\mathrm{xxx}$ & $\mathrm{xxx}$ \\
\hline Veliparib $+500 \mathrm{~V} / \mathrm{cm}, 20 \mathrm{~ms}, 8$ pulses & $\mathrm{xxx}$ & $\mathrm{xxx}$ & $\mathrm{xxx}$ \\
\hline
\end{tabular}

Table.4 Connecting Letter Report from Tukey's HSD test

\begin{tabular}{|l|c|l|}
\hline Level & $\begin{array}{c}\text { Letter } \\
\text { Report }\end{array}$ & $\begin{array}{c}\text { Least } \\
\text { Square } \\
\text { Mean }\end{array}$ \\
\hline Control & $\mathrm{A}$ & 100 \\
\hline $1 \mu \mathrm{M}$ & $\mathrm{AB}$ & 88.06 \\
\hline $10 \mu \mathrm{M}$ & $\mathrm{BC}$ & 65.42 \\
\hline $100 \mu \mathrm{M}$ & $\mathrm{CD}$ & 54.22 \\
\hline $50 \mu \mathrm{M}$ & $\mathrm{CD}$ & 43.99 \\
\hline $300 \mu \mathrm{M}$ & $\mathrm{CD}$ & 34.89 \\
\hline $330 \mu \mathrm{M}$ & $\mathrm{D}$ & 23.57 \\
\hline $500 \mu \mathrm{M}$ & $\mathrm{D}$ & 30.39 \\
\hline
\end{tabular}

Table.5 Connecting Letter Report from Tukey's HSD test on treatments

\begin{tabular}{|l|c|c|}
\hline Level & Letter & $\begin{array}{l}\text { Least Square } \\
\text { Mean }\end{array}$ \\
\hline Control & A & 94.136667 \\
\hline Drug only & A & 93.800000 \\
\hline $\begin{array}{l}1200 \mathrm{~V} / \mathrm{cm}, 100 \mu \mathrm{s}, 8 \\
\text { pulses }\end{array}$ & A & 87.027778 \\
\hline $500 \mathrm{~V} / \mathrm{cm}, 20 \mathrm{~ms}, 8$ pulses & B & 69.575556 \\
\hline
\end{tabular}


Fig.4 Procedure for in-vitro electroporation

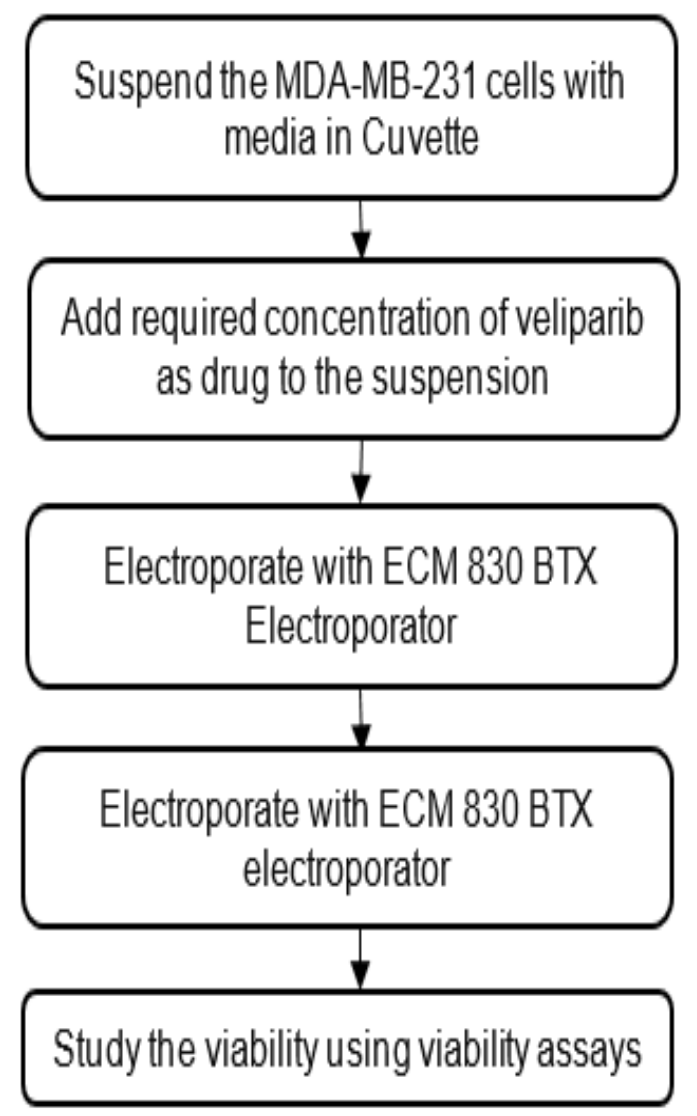

Fig.5 Dose curve of Veliparib on MDA-MB-231 cells without electroporation

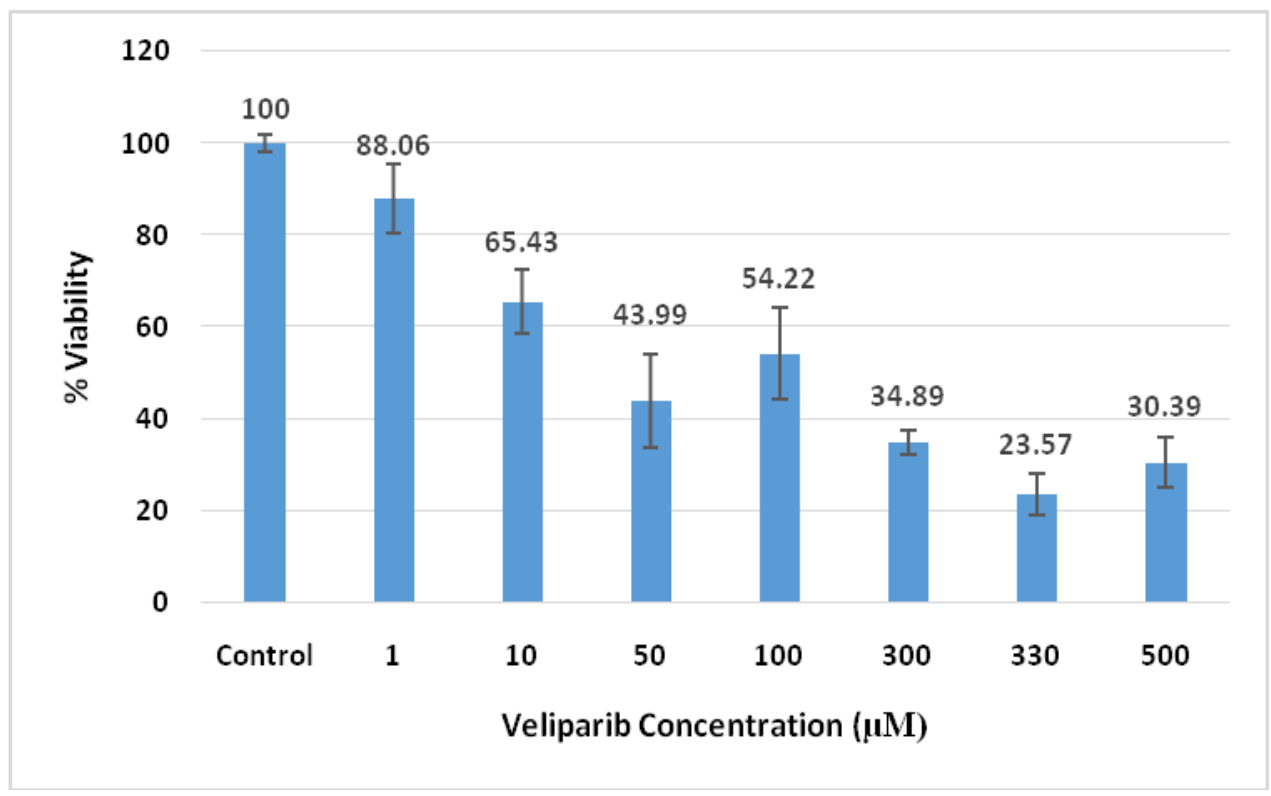


Fig.6 Viabilities of MDA-MB-231 cells without any treatment, with Veliparib alone $(330 \mu \mathrm{M})$ and combination of Veliparib $(330 \mu \mathrm{M})$ and electroporation

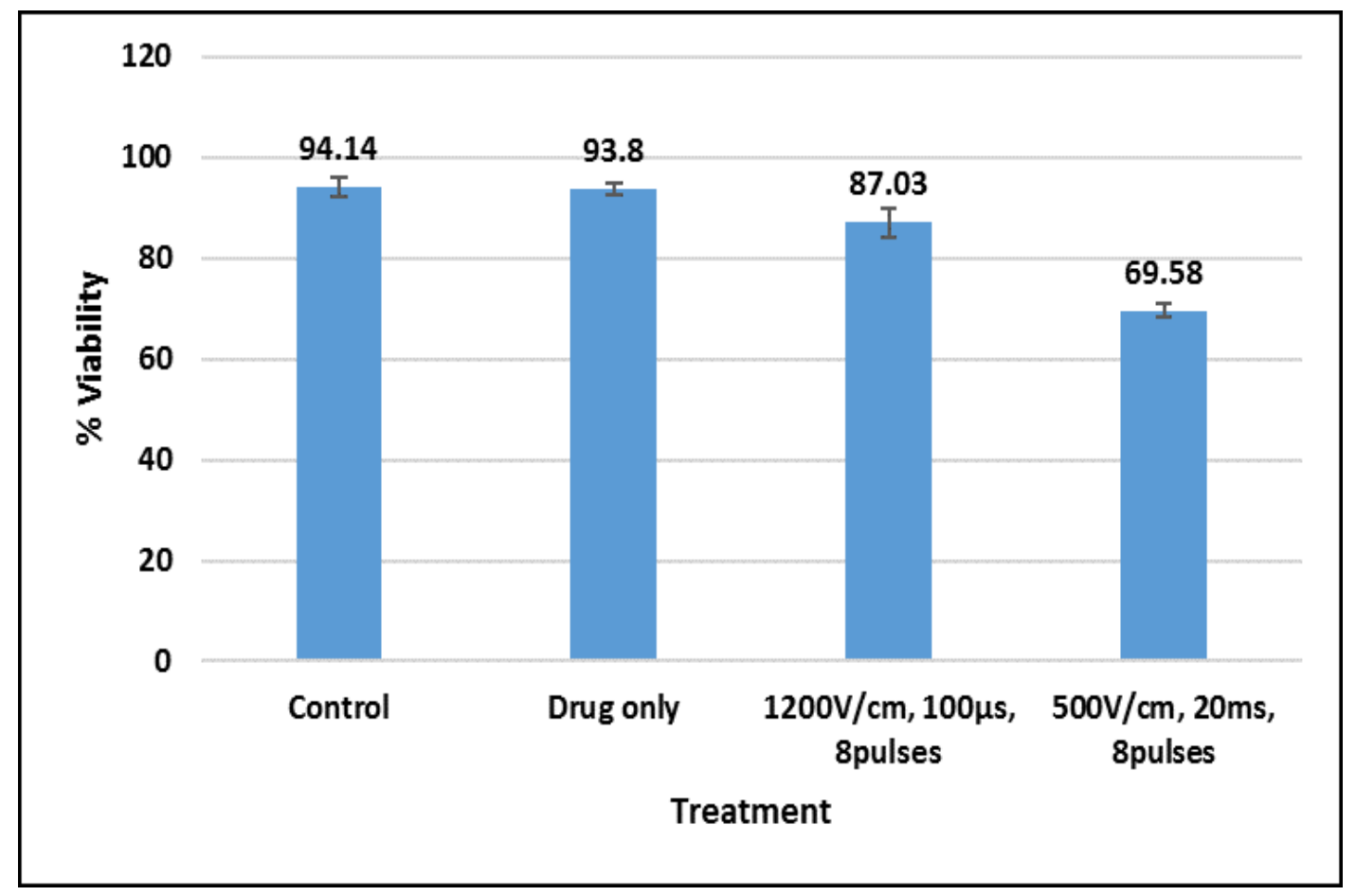

Fig.7 Viabilities of MDA-MB-231 cells after 24, 48 and 72 hours: without any treatment, with Veliparib alone $(330 \mu \mathrm{M})$, and combination of Veliparib $(330 \mu \mathrm{M})$ and electroporation

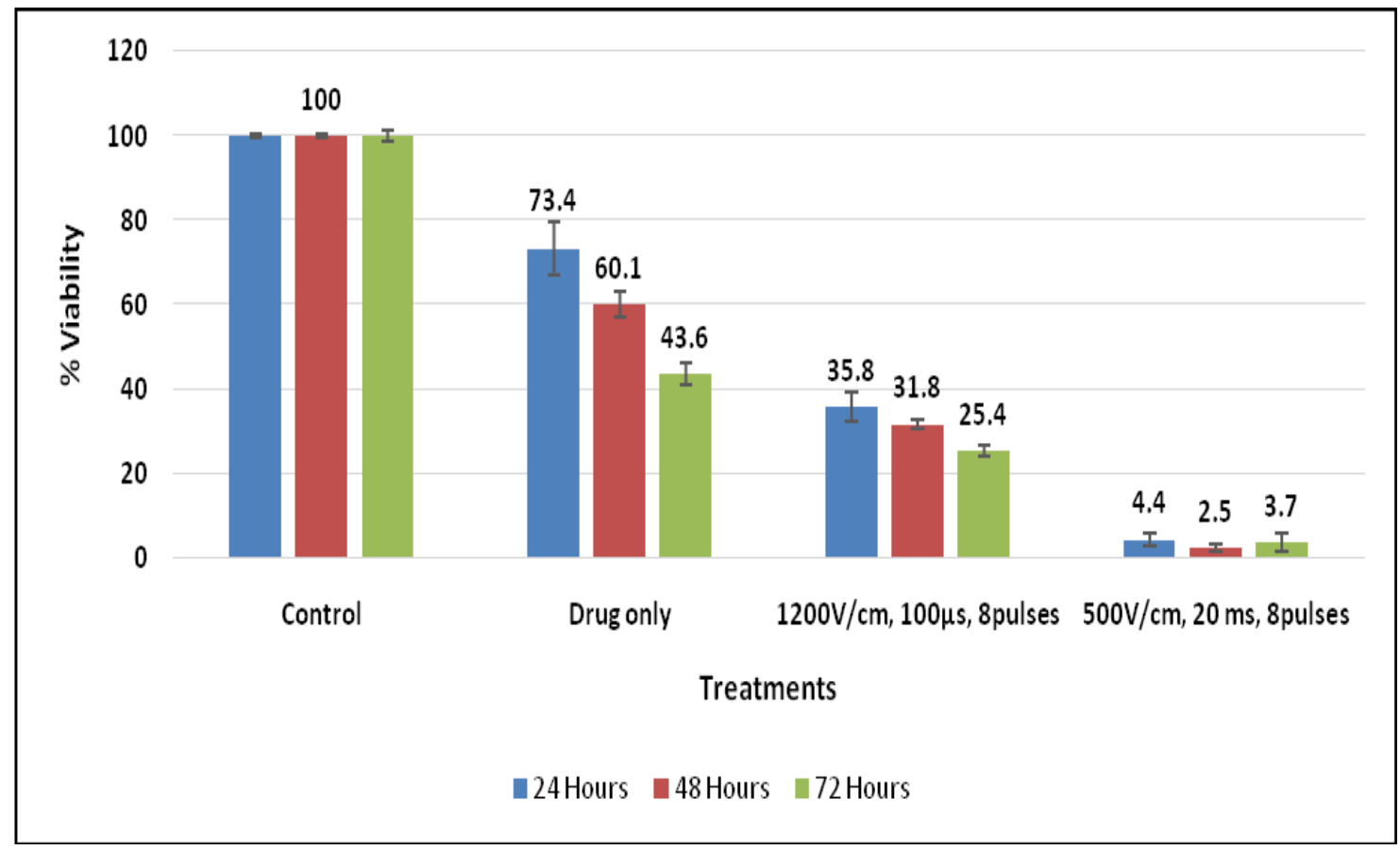


Fig.8 Typical microscopic images of MDA-MB-231 cells after 24, 48 and 72 hours: without any treatment, with Veliparib alone $(330 \mu \mathrm{M})$, and combination of Veliparib $(330 \mu \mathrm{M})$ and electroporation

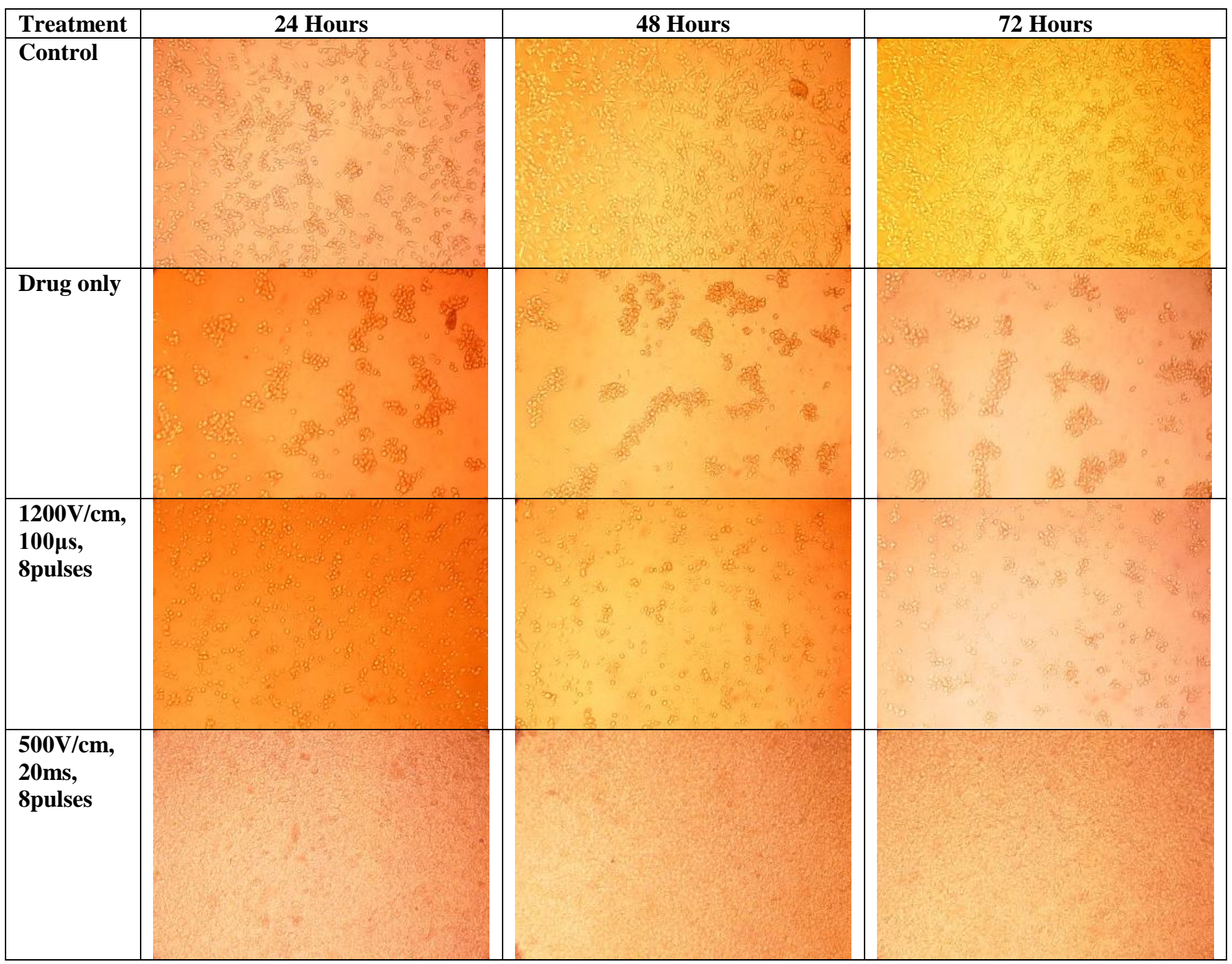

Veliparib in combination with low duration electrical pulses of $1200 \mathrm{~V} / \mathrm{cm}, 100 \mu \mathrm{s}, 8$ pulses also shares the same letter ' $A$ ' with control and drug only treatments, indicating the inefficiency of these low duration pulses. Treatment with long duration pulses of $500 \mathrm{~V} / \mathrm{cm}, 20 \mathrm{~ms}$, 8pulses has the letter B, different from those of control, and drug only, and electroporation treatment using $1200 \mathrm{~V} / \mathrm{cm}$ pulses, thus significantly different.

\section{Viability study using MTT assay}

The viabilities of MDA-MB-231 cells 24, 48 and 72 hours following the treatment were measured with MTT assay. Figure 7 illustrates the viabilities at the various conditions, including, control, drug only, and the two conditions of Veliparib and electroporation. All viabilities are normalized with respect to the viability of control. The drug only samples had a viability of $73.4 \%$ after 24 hours, which dropped down by $\sim 18 \%$ to reach $\sim 60 \%$ after 48 hours, which further dropped by $\sim 27 \%$ to reach $\sim 44 \%$ after 72 hours of treatment. These reductions indicate the long term efficacy of the drug. Similar results were also obtained for the Veliparib+electrical pulses treated samples.

Treatment with higher intensity, lower duration electrical pulses of $1200 \mathrm{~V} / \mathrm{cm}, 100 \mu \mathrm{s}, 8$ pulses yielded the viability of $\sim 36 \%$ after 24 hours and a drop of $11 \%$ and $20 \%$ was observed after 48 and 72 hours of the treatment. The treatment with $500 \mathrm{~V} / \mathrm{cm}, 20 \mathrm{~ms}, 8$ pulses with Veliparib yielded viability of $4.4 \%$, after 24 hours, which dropped to $2.5 \%$, after 48 hours and increased to $3.7 \%$ after 72 
hours. This low viability or high cell kill may be due to the high energy content of the $500 \mathrm{~V} / \mathrm{cm}, 20 \mathrm{~ms}, 8$ pulses, which is sufficient to cause cell death. It can be observed that by varying the pulse intensity, duration, it is possible to obtain desired cell kill.

Figure 8 shows the typical microscopic images of MDAMB-231 cells after 24,48 and 72 hours of the treatment. It can be observed that for control, the cell confluency increases with time. In cells treated with Veliparib, the cells form clusters which may be due to the alterations in cell to cell and cell-substratum interactions. Previously, Masiello et al have also observed such alterations in MDA-MB-231 cell line exposed to microgravity (Masiello et al., 2014). In the cells treated with $1200 \mathrm{~V} / \mathrm{cm}, 100 \mu \mathrm{s}$, 8pulses, the cells appear to lose their adhesive properties, but unlike the drug only treatment, they do not form clusters. This highlights the differential mechanism when MDA-MBA-231 cells were treated with the combination of drug and electrical pulses. Further study is required to understand the exact mechanism. Another study conducted by Pehlivanova, et $a l$. also indicate that electroporation can reduce the cell adhesion and replication (Pehlivanova et al., 2012), which is in line with our study. Microscopic pictures obtained under low intensity, high duration electrical pulses of $500 \mathrm{~V} / \mathrm{cm}, 20 \mathrm{~ms}, 8$ pulses indicate the absence of live cells after 24,48 and 72 hours of treatment. This is in agreement with viability count obtained with MTT assay (Figure 7 ), where $4.4 \%, 2.5 \%$, and $3.7 \%$ of live cells were observed after 24,48 and 72 hours.

\section{Conclusion}

Triple Negative Breast Cancers are hard to be treated, due to the lack of the three receptors, and hence majority of therapies fail to work. In this study, the feasibility of Veliparib and electroporation as alternate therapy has been explored. Towards this, In this study Veliparib at a concentration of $330 \mu \mathrm{M}$ was used in combination with electrical pulses on MDA-MB-231 cell line. Various pulses of different intensity and pulse duration were used to enhance the Veliparib uptake against the cell membrane.

Results indicate that the treatment with Veliparib and electrical pulses is effective for treating TNBCs. Immediately after the treatment, low intensity, high duration electrical pulses of $500 \mathrm{~V} / \mathrm{cm}, 20 \mathrm{~ms}, 8$ pulses yielded cell kill of $\sim 30 \%$ compared to $\sim 13 \%$ with high intensity, low duration pulses of $1200 \mathrm{~V} / \mathrm{cm}, 100 \mu \mathrm{s}, 8$ pulses and $\sim 6 \%$ with drug only and control. After 72 hours of treatment $\sim 6$ times lower viability is obtained with $500 \mathrm{~V} / \mathrm{cm}, 20 \mathrm{~ms}$, 8pulses compared to $1200 \mathrm{~V} / \mathrm{cm}$, $100 \mu \mathrm{s}$, 8pulses, and $\sim 11$ times lower compared to viability of drug only treatment. Thus, it is concluded that low intensity, high duration electrical pulses are more effective in combination with Veliparib to treat TNBCs.

Optimal efficiency and desired amount of cell kill could be achieved optimizing the parameters of electrical pulses. This treatment could be transferred to clinical practice quickly as an alternate therapy against triple negative breast cancers.

\section{Acknowledgement}

We are very grateful to Mr. Lin-Yang Cheng for his kind support in establishing statistical model for the study. We also thank Mr. Vishveswaran Jothi for his assistance in carrying out the present study.

\section{References}

Abdi H., Williams L.J. 2010. Tukey's honestly significant difference (HSD) test. Encyclopedia Res. Des., 1: 1-5 10.4135/9781412961288.n181.

Binggeli, R., \& Weinstein, R.C. 1986. Membrane potentials and sodium channels: Hypotheses for growth regulation and cancer formation based on changes in sodium channels and gap junctions. $J$. Theoretical Biol., 123(4): 377-401. doi:10.1016/s0022-5193(86)80209-0.

Campana, L. G., Mocellin, S., Basso, M., Puccetti, O., Salvo, G. L., Chiarion-Sileni, V., et al. 2009. Bleomycin-Based Electrochemotherapy: Clinical Outcome from a Single Institution's Experience with 52 Patients. Annals of Surgical Oncol., 16(1): 191-199. doi:10.1245/s10434-008-0204-8.

Chavez, K.J., Garimella, S.V. and Lipkowitz, S. 2011. 'Triple negative breast cancer cell lines: One tool in the search for better treatment of triple negative breast cancer', Breast Dis., 32(1-2): pp. 35-48. doi: 10.3233/bd-2010-0307.

Desantis, C., Ma, J., Bryan, L., \& Jemal, A. 2013. Breast cancer statistics, 2013. CA: A Cancer $J$. Clinicians, 64(1): 52-62. doi:10.3322/caac.21203.

Donawho, C.K., et al. 2007. ABT-888, an Orally Active Poly (ADP-Ribose) Polymerase Inhibitor that Potentiates DNA-Damaging Agents in Preclinical Tumor Models. Clin. Cancer Res., 13(9): 2728 LP-2737. doi: 10.1158/1078-0432.CCR-06-3039. 
Ferlay, J., et al. 2014. Cancer incidence and mortality worldwide: Sources, methods and major patterns in GLOBOCAN 2012. Int. J. Cancer, 136(5): doi:10.1002/ijc. 29210.

Foulkes, W.D., Smith, I.E., \& Reis-Filho, J.S. 2010. Triple-Negative Breast Cancer. New England J. Med., $\quad 363(20)$ : 1938-1948. doi:10.1056/nejmra1001389.

Gehl, J., \& Geertsen, P. F. 2000. Efficient palliation of hemorrhaging malignant melanoma skin metastases by electrochemotherapy. Melanoma Res., 10(6): 585-589. doi:10.1097/00008390200012000-00011.

Gerlier, D., \& Thomasset, N. 1986. Use of MTT colorimetric assay to measure cell activation. $J$. Immunol. Methods, 94(1-2): 57-63. doi:10.1016/0022-1759(86)90215-2.

Holliday, D.L., \& Speirs, V. 2011. Choosing the right cell line for breast cancer research. Breast Cancer Res., 13(4): 215. doi:10.1186/bcr2889.

http://www.medchemexpress.com/DataSheet/Veliparibdihydrochloride.html. Retrieved Jan 2017.

Inbar-Rozensal, D., Castiel, A., Visochek, L., Castel, D., Dantzer, F., Izraeli, S., \& Cohen-Armon, M. 2009. A selective eradication of human nonhereditary breast cancer cells by phenanthridine-derived polyADP-ribose polymerase inhibitors. Breast Cancer Res., 11(6). doi:10.1186/bcr2445.

Keam, B., et al. 2007. Prognostic impact of clinicopathologic parameters in stage II/III breast cancer treated with neoadjuvant docetaxel and doxorubicin chemotherapy: paradoxical features of the triple negative breast cancer. BMC Cancer, 7(1): doi: 10.1186/1471-2407-7-203.

Lee, J., Stacy, A., Yu, M., \& Kohn, E. C. 2013. Abstract A249: Navitoclax and veliparib yield cytotoxicity with lower doses than used for single agents in women's cancers. Molecular Cancer Therapeutics, 12(11) Supplement. doi:10.1158/1535-7163.targ13-a249.

Masiello, M.G., et al. 2014. Phenotypic Switch Induced by Simulated Microgravity on MDA-MB-231 Breast Cancer Cells. BioMed. Res. Int., 1-12. doi:10.1155/2014/652434.

Meerloo, J.V., Kaspers, G.J., \& Cloos, J. 2011. Cell Sensitivity Assays: The MTT Assay. Methods in Mol. Biol. Cancer Cell Culture, 237-245. doi:10.1007/978-1-61779-080-5_20.

Montgomery, D.C. 2013. Design And Analysis of Experiments, New York: John Wiley \& Sons.
Murai, J., et al. 2012. Trapping of PARP1 and PARP2 by Clinical PARP Inhibitors. Cancer Res., 72(21): 5588-5599. doi:10.1158/0008-5472. can-12-2753.

Orr, C. W., Yoshikawa-Fukada, M., \& Ebert, J. D. 1972. Potassium: Effect on DNA Synthesis and Multiplication of Baby-Hamster Kidney Cells. Proceedings of the National Academy of Sciences, 69(1): 243-247. doi:10.1073/pnas.69.1.243.

Pahuja, S., Beumer J. H., Appleman, J. L., Puhalla, S. 2015. A phase I study of veliparib (ABT-888) in combination with weekly carboplatin and paclitaxel in advanced solid malignancies and enriched for triple-negative breast cancer (TNBC). J. Clin. Oncol., 33.

Pehlivanova, V.N., Tsoneva, I.H., \& Tzoneva, R.D. 2012. Multiple effects of electroporation on the adhesive behaviour of breast cancer cells and fibroblasts. Cancer Cell Int., 12(1): 9. doi:10.1186/1475-2867-12-9.

Product catalog, Available: http://www.cellbiolabs.com/mda-mb-231-reportercells. Jan 2017.

Redmann, K., Müller, V., Tanneberger, S., Kalkoff, W. 1972. The membrane potential of primary ovarian tumor cells in vitro and its dependence on the cell cycle. Acta Biol. Med. Ger., 28(5): 853-6.

Sandhu, G.S., Erqou, S., Patterson, H., \& Mathew, A. 2016. Prevalence of Triple-Negative Breast Cancer in India: Systematic Review and MetaAnalysis. J. Global Oncol., doi:10.1200/jgo.2016.005397.

Scott, J.E. 2003. Conn's Biological Stains. A Handbook of Dyes, Stains and Flurochromes for Use in Biology and Medicine. J. Anatomy, 203(4): 433433. doi:10.1046/j.1469-7580.2003.00223.x.

Sonnenblick, A., Azambuja, E.D., Azim, H.A., \& Piccart, M. 2014. An update on PARP inhibitorsmoving to the adjuvant setting. Nature Reviews Clin. Oncol., 12(1): 27-41. doi:10.1038/nrclinonc.2014.163.

Stockert, J.C., Blázquez-Castro, A., Cañete, M., Horobin, R. W., \& Villanueva, Á. 2012. MTT assay for cell viability: Intracellular localization of the formazan product is in lipid droplets. Acta Histochemica, 114(8):

785-796. doi:10.1016/j.acthis.2012.01.006.

Stover, D.G., Bell, C.F., \& Tolaney, S.M. 2016. Neoadjuvant and Adjuvant Chemotherapy Considerations for Triple-Negative Breast Cancer. American J. Hematol. Oncol., 6-12. 
Sundararajan, R., et al. 2012. Effective proliferation control of human cancer cells using electrical pulses. IEEE Transactions on Dielectrics and Electrical Insulation, 19(6): 2225-2236. doi:10.1109/tdei.2012.6396984.

Teissie, J., \& Tsong, T. Y. 1981. Electric field induced transient pores in phospholipid bilayer vesicles. Biochem., $\quad 20(6)$ : $1548-1554$. doi:10.1021/bi00509a022.

The PARP Inhibitors: down but not out. www.onclive.com. Retrieved Jan 2017.

Tukey, J.W. 1953. "The problem of multiple comparisons." Unpublished Notes, Princeton University.

Velic, D., Couturier, A., Ferreira, M., Rodrigue, A., Poirier, G., Fleury, F., \& Masson, J. 2015. DNA Damage Signalling and Repair Inhibitors: The

\section{How to cite this article:}

Lakshya Mittal, Vishak Raman, Ignacio Camarillo and Raji Sundararajan. 2017. Electrical Pulse-Mediated Veliparib for the Treatment of Triple Negative Breast Cancer: An in vitro Model Study. Int.J.Curr.Res.Aca.Rev. 5(3), 53-64. doi: https://doi.org/10.20546/ijcrar.2017.503.009
Long-Sought-After Achilles' Heel of Cancer. Biomolecules, 5(4): 3204-3259. doi:10.3390/biom5043204.

Wagner, L. 2015. Profile of veliparib and its potential in the treatment of solid tumors. OncoTargets and Therapy, doi:10.2147/ott.s69935.

Weaver, J. 2000. Electroporation of cells and tissues. IEEE Transactions on Plasma Science, 28(1): 2433. doi:10.1109/27.84282.

Weinberg, R. A. 2007. The Biol. Cancer, New York: Garland Science.

Zhang, J., et al. 2014. Cisplatin and gemcitabine as the first line therapy in metastatic triple negative breast cancer. Int. J. Cancer, 136(1): 204-211. doi:10.1002/ijc.28966. 